\title{
La frontera norte de México y la crisis de 1982: algunos comentarios preliminares
}

\author{
Jesús Tamayo \\ Centro de Investigación y Docencia Económica, A.C.
}

\section{Resumen}

Este documento intenta, en una primera parte, a partir de la secuencia cronológica de los hechos del segundo semestre de 1982, analizar los condicionamientos externos al sistema mexicano y algunas de las respuestas mexicanas a ello, materializadas en decisiones de política económica. Enseguida se revisan los efectos o repercusiones propiamente fronterizos, así como algunas respuestas e iniciativas regionales. La segunda parte de este documento resalta algunas tendencias económicas globales que permiten prever un escenario regional en el corto plazo. Finalmente, se cuestiona la posibilidad de que los sectores privados y algunos grupos de la clase política fronteriza apoyen y favorezcan la actual política económica orientada a la sustitución de importaciones.

Palabras Clave: devaluación, economía, frontera, clase política fronteriza, tendencias económicas, importaciones.

\begin{abstract}
The first part of this document tries, starting from a chronological sequence of the events happened during the second semester of 1982, to analyze the external conditioning factors of the Mexican system as well as some of the answers offered by Mexican entities. These answers were materialized through decisions on political economics. Secondly, effects or repercussions that are proper of the border region are reviewed, along with some regional answers and initiatives. The second part of this document highlights some of the global economical trends that allow us to preview a short term regional scenario. Finally, this document is questioning the possibility that private sectors together with certain groups of the politician class support and favor the current economic policy that intends the substitutions of importing.
\end{abstract}

Keywords: devaluation, economics, border, border political class, economical trends, importing. 


\title{
LA FRONTERA NORTE DE MEXICO Y LA CRISIS DE 1982: ALGUNOS COMENTARIOS PRELIMINARES.
}

\author{
Por: \\ Jesús Tamayo \\ Investigador del Cen tro de Investigación \\ y Docencia Económicas, A.C.
}

\section{PRESENTACION}

Las devaluaciones de febrero, agosto y diciembre del pasado año, el control de cambios, y la escasez generalizada de divisas en los circuitos financieros nacionales han tenido un impacto regional fronterizo de magnitud inusitada cuyos efectos en el mediano y largo plazo son, en mucho, todavía impredecibles.

En principio, las necesidades de estado privaron sobre cualquier consideración de orden regional; en fechas más recientes, aquéllas parecieron ceder ante los intereses privados locales que, además, contaron con total visibilidad periodística. Independientemente del resultado de esta primera escaramuza, la crisis financiera se prevé larga, y la negociación acerca del peso que cada uno de los sectores sociales nacionales habrá de sobrellevar en los años por venir está apenas iniciándose; asimismo, la discusión nacional acerca del papel de la periferia fronteriza en el proyecto económico nacional de los próximos años, está también lejos de haberse terminado.

Este documento intenta, en una primera parte, a partir de la secuencia cronológica de los hechos del segundo semestre del pasado año, reproducir el contrapunto que conforman: los condicionamientos externos al sistema mexicano; algunas de las respuestas mexicanas a ello, materializadas en decisiones de política económica; y, finalmente, los efectos o repercusiones propiamente fronterizos, as 1 como algunas respuestas e iniciativas regionales.

La segunda parte de este documento apunta algunas tendencias económicas globales que permiten prever un cierto escenario regional en el corto plazo; finalmente, se pregunta este trabajo acerca de la posibilidad de que los sectores privados y algunos grupos de la clase politica fronteriza, apoyen y favorezcan la actual política económica, orientada a la sustitución de importaciones. 
La crisis en la frontera no puede entenderse plenamente sin aproximanos previamente, así sea en sus líneas más generales, a la crisis económica nacional. Aquélla es un reflejo, frecuentemente ampliado, del agotamiento del modelo de desarrollo económico de corte expansionista que materializó en graves problemas en el sector externo de nuestra economfa. La disponibilidad de petróleo hizo posible mantener en los últimos años un cuantioso flujo de recursos a la expansión económica, pública y privada, al subsidio de las importaciones, al enriquecimiento de algunos sectores de la burocrcia política y a la especulación financiera. El déficit acumulado en la ba lanza de pagos llevó la deuda externa a niveles inusitados. Repentinamente. el atascamiento de la única palanca disponible para conservar y reproducir nuestro crédito externo nos condujo a la insolvencia financiera, eufemisticamente llamada crisis de liquidez o de caja. Ello ha obligado a replantear en otros términos el proyecto económico nacional y ha inducido la renegociación entre la clase política y el resto de los sectores sociales a fin de determinar el peso de la crisis que en los futuros años habrá de sobrellevecada uno de ellos.

\section{ANTECEDENTES}

Los antecedentes de la crisis financiera nacional que se manifiesta abiertamente en febrero de 1982 y que parece llegar a su clímax en agosto y septiembre del mismo año parten de 1976 cuando, al inicio de la administración de López Portillo, se tomó la decisión política de expandir el sector petrolero y sobre esta base desarrollar la planta industrial nacional. Para ello se utilizaría un peso sobrevaluado como importante instrumento en el proceso de expansión. En efecto, el Banco de México impediría poco después que la tasa de cambio, supuestamente flotante creciera más allá de ciertos límites; ${ }^{1}$ la disponibilidad de divisas petroleras permitiría sostener indefinidamente el tope máximo establecido extraoficialmente para la tasa de cambio.

A los pocos meses, sin embargo, factores externos e internos hicieron evidente no solo la escasa eficiencia de una tasa de cambio fija y progresivamente sobrevaluada sino también de la política económica global. Las altas tasas de interés prevalecientes en el mercado financiero internacional (a las 1

En los últimos años, los centros financieros internacionales habrian promovido la existencia de tasas flotantes de cambio a fin de eliminar distorsiones y estimular el comercio internacional. Sin embargo, la vulnerabilidad de los gobiernos nacionales ante corridas o estampidas especulativas que provocan cambios bruscos de valor, hacen volver los ojos a algunos analistas a los antiguos sistemas rigidos y les hace concluir en la necesidad de un sistema de flotación restringida. 
que en lo interno se añadía un diferencial por concepto de riesgo devaluatorio) llevaron nuestras tasas internas de interés a niveles muy elevados. El alto precio del dinero deterioró progresivamente la actividad industrial, encareció los precios de los productos manufacturados, les restó competitividad y, consecuentemente, desaceleró las exportaciones no-petroleras. La inflación interna, creciente, operó en el mismo sentido; al ser significativamente mayor que la correspondiente tasa estadunidense, aceleró la sobrevaluación del peso; ello subsidió todo tipo de importaciones y desalentó, aún más, las exportaciones mexicanas ${ }^{2}$. En este cscenario, se desplomaron los ingresos por concepto de exportaciones no-petroleras, al tiempo que crecieron significativamente los egresos por importaciones y por compra de servicios en el extranjero por parte de sectores de mexicanos enriquecidos. ${ }^{3}$.

Dentro del conjunto de importadores mexicanos subsidiados en el período en cuestión, es decir, dentro de los receptores de transferencias víatasa de cambio, se contó muy principalmente la población fronteriza del norte de México, importadora tradicional de buen parte de sus bienes de consumo. ${ }^{4}$ Durante cerca de cinco años, la creciente sobrevaluación de nuestra

\section{2}

Véase un analisis detallado de la coyuntura económica de los últimos meses de 1981 en el artículo colectivo de los analistas del Departamento de Economía Mexicana del CWE:

La noche de un sexenio dificil, en Nexos (50), febrero de 1982.

El Comunicado del Banco de México en que se anuncia que esa institución se retirará temporalmente del mercado de cambios (publicado en Comercio Exterior, Vol. 32, No. 3, México, marzo de 1982), proporciona la interpretación oficial de los acontecimientos. 3

Entre los principales beneficiarios de la política económica de los últimos años no sólo se encontró el sector empresarial importador, público y privado, también se contó la pequeña burguesía urbana, importadora de todo tipo de bienes de consumo estadunidense. Este sector, beneficiario por arrastre fe la sobrevaluación del peso pronto descubrió lo relativamente barato que le resultaba, por ejemplo, hacer turismo o comprar bienes inmuebles o servicios médicos en el extranjero.

H. Rudnitsky, en la revista Forbes, señaló desde los primeros meses del año que la salida de capitales desde México antes de la primera devaluación de febrero, ascendia a 100 millones de dólares diarios. Forbes, 15 de marzo de 1982. Antes de la devaluación, las revistas Fortune y Texas Business señalaban que los mexicanos tenían depositados en la banca tejana 16.4 mil millones de dólares y que .as inversiones mexicanas en bienes raices en las principales localidades del sur de Texas habían crecido de 2000 a 6000 millones de dólares.

El 1o. de septiembre de 1982, José López Portillo señalaría que las cuentas bancarias recientes de mexicanos en el exterior ascendían, por lo menos a 14 mil millones de dólares y que el valor de los rmuebles urbanos y rurales en Estados Unidos, propiedad de mexicanos, era estinado en $25 \mathrm{mil} \mathrm{mi-}$ Jones de dólares.

$+$

El elevado contenido importado del consumo en aquellas zonas es su característica económica más sobresaliente; cllo materializaba, hasta agosto de 1982, tanto en Ios numerosos productos estadouniJenses etiquetados y vendidos en dólares en los mercados urbanos del extremo norte como cn las tamjein numerosas compras hechas por mexicanos en las vecinas localidades estadounidenses. Es impor- 
moneda en relación al dólar le subsidió la compra, de suyo elevada, de bienes y servicios pagados con esa divisa. El comercio de las vecinas localidades fronterizas estadounidenses se incrementó así a punto tal que, en algunos casos, se hizo dependiente del consumo mexicano. ${ }^{5}$ El comercio de bienes importados en el lado mexicano de la frontera también floreció espléndidamente. ${ }^{6}$ En etapas más recientes, a la demanda propiamente fronteriza se sumó buena parte de la del interior del país y el poder de compra de los mexicanos se hizo sentir muy dentro del territorio estadunidense. ${ }^{\text {. }}$.

En el período en cuestión, la tasa de cambio prevaleciente hacía ver relativamente caros los escasos bienes mexicanos que llegaban al extremo norte. No hacía mucho, en la primera mitad de los años setenta, los CEDIS habían alentado el envío de artículos mexicanos a la frontera, pero la sobrevaluación del peso habła disuelto progresivamente los efectos de aquel

tante tener presente que a los residentes fronterizos, al contrario de los turistas mexicanos, si les es en buena medida inevitable el consumo de bienes importados. Razones geográficas, históricas, y económicas explican que nuestros mercados fronterizos no sean hoy, de jurisdicción predominante del capital nacional. Cfr.: Jesús Tamayo, La integración de la población fronteriza a la producción y al consumo de bienes estadunidenses: ¿Interdependencia o articulación dependiente? El Día, México, 5 y 6 de junio de 1981 . 5

En 1979, dentro del marco de una amplia investigación llevada al cabo en el CIDE, intentamos una aproximación preliminar al volumen de las compras mexicanas en el territorio fronterizo estadounidense. Nuestros resultados mostraron que el año de 1972, McAllen, National City, Harlingen y Laredo eran las localidades más sensibles a las fluctuaciones del gasto mexicano que, en los casos extremos, participaba con más de un tercio de las ventas locales. Cfr.: La maquila de exportación en las zonas fronterizas del norte de México (reporte final de investigación) Centro de Investigacion y Docencia Economicas, A.C. México, 1979. (mimeo).

6

Es bien conocido que la actividad economica de la mayoría de nuestras localidades fronterizas nació especializada, básicamente orientada a las actividades terciarias. Todavía en 1970, cinco años después de iniciado el Programa de Industrialización Fronteriza (PIF), aquellas localidades mostraron una mayor especialización en el comercio y los servicios que el conjunto de las circunscripciones político-administrativas (municipios) más densificadas del país. Cfr.: La maquila de exportación en las zonas... CIDE, op. cit.

7

Según un estudio de la Cámara de Comercio de la ciudad de San Antonio, Texas, en 1980 llegaron a los Estados Unidos 3.2 millones de turistas que en total gastaron 2600 millones de dólares, mismos que, siguiendo la distribución apuntada por el Departamento de Comercio, debieron haberse distribuido en la siguiente forma:

Los Angeles, 960 mil turistas mexicanos que gastaron $\$ 780$ millones, San Antonio, 512 mil turistas mexicanos que gastaron $\$ 416$ millones, Houston, 480 mil turistas mexicanos que gastaron $\$ 390$ millones, S. Francisco, 320 mil turistas mexicanos que gastaron $\$ 260$ millones, otras cdes. 928 mil turistas mexicanos que gastaron $\$ 754$ millones, Uno más Uno, 8 de diciembre de 1981 
programa. ${ }^{8}$ En suma, la polftica económica global 1976-1981, en el extremo norte de México tendió a impulsar el ya de por sí elevado consumo de bienes importados. El beneficiario directo fue el sector comercial de bienes duraderos estadounidenses, principalmente electrodomésticos, sector que se desarrolló a uno y otro lado de la frontera con la creciente propensión regional a importar. ${ }^{9}$ El sector maquilador fronterizo y el débil sector manufacturero no maquilador, por su parte, no mostraron señales de haber sido afectados significativamente por la política económica en vigor.

\section{LA CRISIS PETROLERA.}

Hasta 1981, México había registrado un crecimiento económico sin precedente (más del $8 \%$ anual en los últimos años). A nivel internacional era considerado como un caso especial entre las naciones en desarrollo. Ello cristalizaba, se decfa internamente, en la confianza de los banqueros internacionales en el país y, consecuentemente, en los créditos que México había recibido. Sin embargo, a mediados de 1981 , la reducción en el precio del crudo en los mercados internacionales, reducción cuidadosamente buscada por los países compradores, colocó a la economía mexicana en posición de alerta. Reducidos los ingresos por concepto de exportaciones petroleras, el déficit en balanza de pagos se incrementó aceleradamente y tuvo que ser financiado con créditos externos. La situación había cambiado repentinamente. Si bien los banqueros siguieron ofreciendo créditos, disminuyeron las ofertas y se fijaron plazos más cortos -dos años en promedio en vez de siete- para su pago; asimismo fueron elevadas las tasas de interés de los créditos. ${ }^{10}$.

$\overline{8}$

Desde su establecimiento, los CEDIS tuvieron un desarrollo dinámico, incluso mayor que el de las importaciones de artículos gancho. No obstante su éxito, fueron suspendidos después de la devaluación de 1976. Apoyada en aquella experiencia, la Secretaria de Hacienda estableció incentivos similares llamados CEPROFIS. 9

Cifras oficiales mexicanas de 1977 dejaban ver que las importaciones hechas por la población fronteriza, es decir, por el $5 \%$ de la población nacional, alcanzaban más del $18 \%$ de las importaciones globales. El año siguiente, 1978, el total de las importaciones mexicanas, que por razones de organización de las cuentas nacionales mexicanas no incluyen las transacciones fronterizas, ascendió a 183 billones de pesos corrientes; dentro de ellas, las importaciones a perímetros libres fueron 12 billones y las importaciones gancho 2 billones. Ese año, por atra parte, los egresos por transacciones fronterizas ascendieron a 36 billones. Así, la real participación fronteriza en las importaciones nacionales pareciera haber llegado más allá del $20 \%$ Cfr.: Anuario estadístico del comercio exterior mexicano SPP, México, 1978; Banco de México, Informe Anual, 1978. 10

Cfr.: U.S. Banks Reassess Mexico Credit. Lenders Say It's Good Risk, but Are More Cautious. Los Angeles Times, 27 de abril de 1982. 
Ante la inminente crisis, el gobierno mexicano hizo deslizar el peso frente al dólar. La relación de cambio se hizo llegar a 1:26 hacia mediados de febrero. Era obvio, sin embargo, que el ritmo de deslizamiento era lento en relación al impacto económico y político que provocaba la sobrevaluación del peso. ${ }^{11}$ Los llamados presidenciales a la solidaridad no evitaron que en las primeras semanas de febrero, los especuladores, en palabras de José López Portillo, asaltaron el Banco de México. ${ }^{12}$ La fuga de capitales precipitaría así la primera devaluación de $1982 .{ }^{13}$.

En mayo, viviéndose ya las primeras medidas de austeridad, el recién nombrado Secretario de Hacienda, Jesús Silva Herzog, anunció que México se enfrentaria, en los siguientes doce meses, a un período de crecimiento económico nulo y a una tasa de inflación anual no menor del $50 \%,{ }^{14}$ No anunció, sin embargo, que la banca internacional no solo había suspendido nuevos créditos a México, sino también las remesas de divisas sobre créditos previamente aprobados. ${ }^{15} \mathrm{El}$ agotamiento de las reservas era previsible.

La crisis no difunde homogéneamente sus efectos a lo largo del territorio nacional. Las respuestas de política económica del Estado mexicano, la devaluación de la moneda o el control de cambios por ejemplo, tampoco son ubicuas; también la escasez de divisas tiene diferentes niveles y efectos

11

Dos dias antes de la devaluación, el presidente de la CANACINTRA afirmaba que mantener una paridad fija o semi-fija de la moneda ...defiende a industriales de Japón, Europa o EUA de la competencia de la industria mexicana, Portafolios en Excélsior, 16 de febrero de 1982.

12

Primera declaración pública de José López Portillo respecto de la devaluación. Discurso difundido por la televisión mexicana la mañana del 20 de febrero de 1982 .

13

Es posible también que la decisión estadounidense de elevar la tasa prima de interés, decisión anunciada por esos días, y que pareciera haber provocado profunda molestia en los gobiernos europeos, y que incluso pareciera haber influído en la devaluación de varias monedas europe as, pudiese haber participado la decisión devaluatoria mexicana. Cfr.: Shots heard across the Atlantic, Time, 1o. de marzo de 1982; también Europe vs Reaganomics, Newsweek, 1o. de marzo de 1982.

14

Cfr: : Mexico Forecasts $50 \%$ Inflation, Zero Growth, Los Angeles Times, 19 de mayo de 1982 ; Drastic growth slump predicted for Mexico. San Diego Union, 20 de mayo de 1982.

15

La discusión acerca de la situación económica nacional estuvo condicionada por el calendario político mexicano. Las elecciones presidenciales ciertamente restarían visibilidad a la creciente inflación interna que conducfa casi inexorablemente a una segunda devaluación. Así, de febrero a julio, junto a los grandes movimientos especulativos de capital que apostaban a la segunda devaluación del peso, la compra de dólares por parte de las clases medias mexicanas se convirtió en práctica necesaria para proteger el ahorro familiar. 
en los diversos espacios y sectores económicos nacionales.

En tanto las localidades urbanas fronterizas están relativamente aisladas del sistema nacional $\mathrm{y}$, en contrapartida, sus economías están relativamente más integradas al sistema económico estadunidense, su población resiente con mayor fuerza los efectos de modificaciones en la tasa de cambio, en el régimen de cambios monetarios, o de la simple escasez generalizada de divisas. ${ }^{16}$ Dicho de otro modo, la población fronteriza se ve mayormente afectada por estos hechos porque si bien gana en pesos, compra en dólares buena parte de sus bienes de consumo.

La devaluación de febrero, como también lo harfan las de agosto y diciembre, incrementó violentamente el costo de la canasta de bienes en . nuestras zonas fronterizas del norte y consecuentemente frenó la tendencia tradicional a consumir productos estadounidenses, reorientando la demanda local hacia bienes de origen nacional. Hasta antes de febrero, casi cualquier bien importado comprado bajo la tasa $1: 26$, resultaba ser más económico que su equivalente nacional: después de febrero, y principalmente después de agosto, la mayoria de los bienes nacionales resultaban más atractivos que sus equivalentes importados comprados a la tasa $1: 70 ;{ }^{17}$ ni qué decir respecto de bienes comprados después de diciembre a la tasa 1:150. Hay que señalar, sin embargo, que la veloz inflación mexicana tiende a borrar la competitividad coyuntural de los bienes mexicanos.

El incremento en el costo de vida (o la disminución del salario real) fronterizo afecta principalmente al conjunto de trabajadores de ingresos fijos. Este lo integran los empleados de la Federación, del Estado, y del Municipio; los obreros y empleados de las maquiladoras; los escasos obreros de la industria manufacturera propiamente dicha; y los empleados del comercio local, quienes enfrentan ahora incluso el desempleo. Otros sectores de trabajadores fronterizos se encuentran mejor colocados para resistir o transferir a otros los efectos de la crisis. En el primer caso se cuentan los vende-

\section{6}

La lejanfa relativa de las localidades fronterizas respecto de los principales centros productores del país, su tamaño, de distribución especial, todo ello, aunado al incipiente desarrollo de planta productiva nacional y a la fortaleza del correspondiente aparato estadounidense, explican la casi ancestral incompetencia de los productos nacionales en aquellos mercados, donde frecuentemente han llegado en condiciones desventajosas del precio, oportunidad, variedad y calidad. Cfr.: Jesús Tamayo, Dos problemas de desarrollo económico fronterizo, en Las Relaciones México-Estados Unidos/I, UNAM/ Nueva Imagen. México, 1980.

17

Cfr.: La devaluación y la zona fronteriza norte Carta de Polttica Exterior Mexicana, año 2 número 2 , México, CIDE, 15 de mayo de 1982 
dores de bienes y servicios al turismo; en el segundo caso se cuentan aquedax que ejercen liberalmente alguna profesión. No falta un sector de trabajadores que incluso se ve relativamente beneficiado con la situación; éste es el de los llamados emigrados, tarjetas verdes, (commuters o green carders); ésess son mexicanos con residencia legal en Estados Unidos que aprovechan zal status para trabajar en territorio estadounidense y vivir en territorio mexics no. ${ }^{18}$.

El comercio mexicano, en general, ha resultado afectado por la criss económica. En la medida en que ésta abate los ingresos reales de las clases mayoritarias, la actividad comercial resiente la reducción del mercado. Los primeros sectores afectados han sido aquellos que comercian con bien cuya demanda es altamente elástica al ingreso, entre los cuales se cuentar nuestras importaciones suntuarias o superfluas. Además, toda devaluación altera el sistema de precios relativos, importante para cualquier importzdor, en especial para el consumidor fronterizo mexicano. Así, no es extrzño que, a nivel regional, entre los primeros afectados por la crisis se cuente comercio fronterizo estadunidense. Asimismo, el comercio regional mexica no de bienes importados ha visto también desplomarse su nivel de actividad Por el contrario, el comercio mexicano de bienes básicos y no duraderos de origen nacional, ha recibido la demanda que progresivamente ha perdido su contraparte norteamericana. ${ }^{19}$.

El sector maquilador fronterizo también resultó beneficiario de la crisis. El valor que tal industria agrega en México a sus productos, valor que se constituye casi totalmente con los salarios pagados a obreros y empleados. se redujo para aquellas empresas en proporción a la devaluación del peso. A lado de la maquila existe un sector manufacturero no maquilador (pequeña

\footnotetext{
18

En algunas localidades, el peso relativo de los inmigrados es muy relevante. Es el caso de San Lus $\mathrm{R}$ ío Colorado, son donde se estima que ascienden a cinco mil trabajadores. Aunque periódicamente el INS (Servicio de Inmigración y Naturalización) les ennumera, no hace pública su magnitud. 19

El comercio regional, mexicano y estadunidense, ha servido de tiempo atrás no solo a la poblaciós fronteriza sino también a los numerosos visitantes mexicanos a la frontera, quienes tradicionalmente aprovechaban su estancia all para internar (las más veces en forma ilegal) artículos de origen estadunidense. El comercio fronterizo sacaba ventaja así del régimen fiscal-comercial de excepción que históricamente ha disfrutado la población del extremo norte de México. Este régimen materializó hasta el 1o. de septiembre de este año en las libres importaciones domésticas legalizadas por el Código Aduanero, en las libres importaciones a la zona libre, y en las importaciones también libres llamadas gancho No es conocido el volumen conjunto de las importaciones fronterizas; es conocido que la aproximación que de ellas el Banco de México bajo el rubro de transacciones fronterizas es una estimacion subvaluada del volumen real. Cfr.: Jesús Tamayo y José Luis Fernández Zonas Fronterizas: México-Estodos Unidos, CIDE, México, 1983. Colección Ensayos (en prensa).
} 
y mediana industria) que tiende a decrecer en forma lenta, pero segura. No es claro si la crisis la beneficiará o por el contrario, acelerará su extinción.

Finalmente, el sector vendedor de servicios a la población visitante estadunidense, la llamada industria turística fronteriza, con la devaluación también quedó en condiciones de incrementar su volumen absoluto de ventas, mismas que habían languidecido a lo largo de los años de sobrevaluación del peso. Sin embargo, el incremento en la venta de servicios turísticos no ha sido inmediato. ${ }^{20}$.

\section{SLUMP FINANCIERO.}

La fuga de divisas del sistema mexicano que, según declaraciones extraoficiales, alcanzó 15 mil millones de dólares en un lapso de dieciocho meses, desembocó en una nueva flotación/devaluación del peso a principios de agosto. En un esfuerzo por proteger a las actividades no - especulativas se acompañó de un sistema de doble paridad, una libre y una controlada. Una semana después, el gobierno mexicano acordó la prohibición de las transferencias de divisas al exterior, y determinó se pagaran en pesos los depósitos nominados en dólares en la banca mexicana; ${ }^{21}$ estos compromisos ascendían a 12 mil millones de pesos, según cifras de la banca privada. ${ }^{22}$ El mes de agosto no solo se caracterizó por el agotamiento final de dólares en el mercado nacional de monedas, sino también por el descontrol del aparato bancario administrativo, por el alto nivel de dolarización de los ahorros, y por la incontenible fuga de capitales.

\section{0}

El potencial visitante fronterizo se mostró hipersensible a las informaciones locales que presentaron entonces una imagen de México que enfatizaba los conflictos sociales, la ineficiencia y corrupción administrativa, así como una supuesta proclividad al socialismo. Esta imagen no habría contribuido mucho a incrementar el volumen de visitantes fronterizos en los últimos meses de $\mathbf{1 9 8 2}$.

21

Cfr.: Reglas para el pago de depósitos bancarios denominados en moneda extranjera, Diario Oficial, 13 de agosto de 1982 .

22

Cfr.: Dollar Freeze Called Act of Desperation, The San Diego Union, 14 de agosto de 1982. Véase también.: Sin reservas ya, el gobierno se allegó los dólares de las cuentas bancarias, Proceso, 16 de agosto de 1982. pp. 23-26.

23

Aguda escasez de dólares en Nogales: careció de divisas el municipio para pagar. Excélsior 19 de agosto de 1982 Incertidumbre y caos al reabrirse el mercado. Uno más Uno 20 de agosto 1982; En Nogales, en menos de 48 horas, bajó la divisa (sic) 35 pesos. Excélsior 21 de agosto; El municipio de Tijuana, en la mayor crisis de su historia. Excélsior 22 de agosto de 1982. La fuga de capitales se aceleró durante agosto; Peso devaluation fails to halt run of dollar The Tribune (San Diego) agosto 10 de 1982; Peso Hits 150 to dollar on black Market. San Diego Union, 16 de agosto 1982; En San Isidro decae el comercio; los bancos crecen con dolares de mexicanos. Excélsior 22 de agosto de 1982. 
La crisis de agosto prácticamente paralizó las transacciones internacionales en la frontera norte. Ello obligó al gobierno federal a anunciar un urgente Plan de Salvación para las zonas fronterizas. El Secretario de Hacienda informó, el miércoles 18 , que dicho plan consistirfa principalmente en la autorización de dólares preferenciales a los comerciantes locales para la compra de bienes básicos y semibásicos, a fin de contrarrestar su eventual escasez en dichas zonas. ${ }^{24} \mathrm{El}$ impacto de la crisis mexicana también repercutió en la economía del suroeste de los Estados Unidos; ello llevó al presidente del Consejo de las Cámaras de Comercio de los Estados Unidos y al gobernador de California, Edmund Brown, a solicitar al presidente Reagan la declaracion de los territorios fronterizos con México como zona de desastre. La ayuda económica del gobierno estadounidense no llegaría, sin embargo, sino hasta los primeros días de septiembre. ${ }^{25}$

El control cambiario decretado el 1o. de septiembre, expresión del agotamiento final de las reservas estatales, suspendió de facto la vigencia real de los regímenes de excepción fiscal - comercial fronterizos; hasta el día 18 se aclararía que quedaban exceptuadas de la necesidad de permiso previo las importaciones que hicieran los residentes fronterizos al amparo de la franquicia que establece la Ley Aduanera. ${ }^{26}$

El breve período de vigencia del control de cambios se caracterizó en las localidades fronterizas por el desabastecimiento de productos básicos, por la estrategia de aceptación de pesos por parte del comercio estaduni-

24

Desde la devaluación de febrero, pero más aún después de la devaluación de agosto, la población fronteriza denunció en varias ocasiones la escasez de bienes básicos en esas zonas. Tal escasez, provocada en buena medida por la vecina población norteamericana, se agudizaba por la creciente demanda local de productos mexicanos derivada de la devaluación. Cfr. U.S. bargain hunters 'sacking' Tijuana shelves The Tribune (San Diego), agosto 12 de 1982; Ahora vienen de E. U. a comprar productos básicos a este lado Uno más Uno 10 de agosto de 1982; Escasean los básicos en la zona fronteriza Uno más Uno, 17 de agosto de 1982.

25

Casi en quiebra, comercios del sur de E.U., Excélsior, 21 de agosto, 1982; Desastre económico en la zona fronteriza de E.U., Uno más Uno, 21 de agosto de $1982 ;$ En McAllen, desplome de ventas pese a atractivas ofertas, Excélsior, 7 de septiembre de 1982. Finalmente, Ayuda económica en E. U., a las ciudades fronterizas del sur, Excélsior, 8 de septiembre, 1982.

26.

Cfr.: Decreto que establece el control generalizado de cambios. Diario Oficial, 1o. de septiembre de 1982, y Acuerdo que sujeta al requisito de permiso previo por parte de la SIC la importación de todas las mercanctas comprendidas en la tarifa de Impuesto General de Importación, incluyendo la importación que de dichas mercancias se realice a las zonas libres del pats, con las excepciones que se indican, hasta el 31 de diciembre de 1983. Diario Oficial, 17 de septiembre de 1982. 
dense, ${ }^{\mathbf{2 7}}$ por la pertinaz escasez de dólares, y por la especulación monetaria apoyada en las casas de cambio del otro lado de la frontera. Fueron también característicos, al decir del entonces director del Banco de México, el inesperado apoyo popular regional a las medidas del 1o. de septiembre, la natural incomprensión del sector empresarial regional, al cual nunca llegaron las prometidas divisas preferenciales, y la actitud conspirativa de la clase política regional que, en algunos casos, encabezó la especulación promoviendo casas de cambio al otro lado de la frontera. ${ }^{28}$.

Pronto el gobierno federal tuvo que dar algunos pasos atrás permitiendo el establecimiento de casas de cambio en la frontera mexicana, es decir, suprimiendo regionalmente el control cambiario, permitiendo después a las empresas fronterizas la apertura de cuentas en dólares en la banca nacionalizada y, finalmente prorrogando temporalmente el régimen de zona libre en el noroeste de Mexico; esta vez, sin embargo, quienes importaran bienes estadunidenses tendrían que emplear sus propios dólares.

La estrategia negociadora de las autoridades mexicanas enfrentadas a la crisis financiera, fue ortodoxa. Consistió en solicitar auxilio al mismo sistema financiero internacional apoyados ahora en algunas autoridades estadounidenses, $y$ en desoir algunos ofrecimientos árabes de apoyo financiero. ${ }^{29}$

El 10 de noviembre, el Secretario de Hacienda y el director del Banco de México, dieron a conocer el texto de la Carta de Intención enviada al FMI por el gobierno mexicano. Ello suponía que se había vencido finalmente la resistencia inicial mexicana a adoptar las medidas de austeridad económica demandadas por aquella institución financiera. El acuerdo preliminar -la aprobación definitiva del FMI se esperaba hasta diciembre- abría la

\section{7}

Con la aceptación de pesos, los norteamericanos habían encontrado la forma de atraer a los mexicanos que ya no acudían como antes a los comercios estadounidenses; simultáneamente, evitaban la entrada de dólares a México. Los pesos captados en aquél lado de la frontera eran remitidos a las maquiladoras para el pago de sus nóminas; se utilizaban también para liquidar saldos con exportadores

${ }_{28}$ mexicanos.

Ello fue señalado en su momento por la prensa mexicana. Cfr.: Funcionarios mexicanos ligados a casas de cambio en E.U., Excélsior, 31 de octubre de 1982. El 8 de noviembre, José Luis Mejías, en su columna Los Intocables, en Excélsior, afirmó que Roberto de la Madrid era propietario de una batería de casas de cambio a ambos lados de la frontera.

29

Cfr.: Publica Financial Tìmes que México rechazó el crédito de Saudiarabia, Excélsior, 5 de octubre de 1982 . 
puerta a la renegociación y reestructuración de la deuda externa y haría posible recibir en los siguientes tres años un total de 4.6 miles de millones de dólares, y concertar créditos adicionales por 6 mil millones en 1983. Por su parte, México se comprometía a abandonar su política de financiar con deuda su desarrollo económico y reducir el déficit del sector público (medido en relación al producto) del $16.5 \%$ al $8.5 \%$, a recortar los subsidios gubernamentales, a reducir la tasa de endeudamiento externo, a incrementar las tasas internas de interés, a desmantelar las barreras arancelarias y no -arancelarias a las mercaderías extranjeras, y a suavizar el control de cambios a fin de volver a la normalidad en las transacciones extranjeras. ${ }^{30}$.

El día 17 el Secretario de Hacienda, Silva Herzog, dijo que el acuerdo no inclura tope salarial alguno; había sido el Fondo el que habra aceptado sin condiciones el programa de reajuste económico de México, afirmo. ${ }^{31}$.

\section{NUEVA POLITICA.}

El día 1o. de diciembre Miguel de la Madrid (MM en lo sucesivo) asumió la Presidencia de la República. En su discurso inaugural anunció un PLAN DE REORDENAMIENTO ECONOMICO que elevaba al rango de medida programática principal una de las condiciones de política económica exigidas por el FMI; la reducción del gasto público. Para asegurar la reducción del déficit del sector público anunció una reforma fiscal (que elevaría los ingresos públicos), y la reestructuración de la administración pública fe. deral. La reducción del aparato burocrático y de la inversión pública se perfilan as ́ como instrumento principal con el que se pretende combatir la inflación y recuperar el dinamismo del desarrollo económico. Otras facetas importantes del Plan de Reordenamiento fueron un programa de protec. cion al empleo y otro de protección y estímulo a los programas de produc. ción, importación y distribución de alimentos básicos En la vertiente polí. tica del Plan destaca la promesa de honestidad y eficacia de la administra. ción pública, y la afirmación de la relevancia cualitativa (rectoría) del sector público (Estado) dentro del régimen de economía mixta.

Vale subrayar que si bien MM afirmó que la nacionalización de la bancé

\section{0}

Cfr.: Carta de Intención enviada por el Gobierno Mexicano al Fondo Monetario Internacional (Texto íntegro publicado en la unidad de México, 11 de noviembre de 1982).

31

Cfr.: Excélsior, 18 de noviembre de 1982. 
era irreversible, sugirió una vuelta a la banca mixta. Anunció también en esa ocasión ajustes próximos al control de cambios, un tipo de cambio realista, controles sobre las importaciones, y la racionalización de la protección fiscal; todo ello bajo el rubro de la reivindicación del control cambiario bajo la austeridad y la soberanfa monetaria del Estado.

El día 10 de diciembre, la nueva administración decretó la apertura parcial del mercado de cambios. ${ }^{32}$ El ajuste en los controles cambiarios tendería ciertamente a suavizar el carácter draconiano de las medidas de los primeros días de septiembre, reduciendo la presión sobre los hipersensibles sectores medios de la población y proporcionándoles un cierto volumen de dólares para sus necesidades inmediatas; el ajuste serviría también para devaluar nuevamente la moneda a través de la modificación de la relación de cambio en los tipos controlados, ${ }^{33}$ cuidando que los deudores de créditos en dólares recibiesen un golpe menos que proporcional al impacto general; buscarıa también asegurar, por la vía del control, el ingreso de las divisas captadas por las exportaciones; finalmente, el ajuste también daría oportunidad para responsabilizar políticamente de las dos vertientes de la crisis (insolvencia financiera y desorden administrativo) a las estrategias populistas de la anterior administración. Explícitamente, el Decreto de Control de Cambios reafirmó la intención gubernamental de .... no trastornar las naturales relaciones económicas y sociales de las poblaciones fronterizas con las zonas extranjeras vecinas. Dijo también que es ... altamente indeseable la vigencia de disposiciones que tienden a ser violadas masivamente; así como (también es inconveniente) el desarrollo del mercado de cambios fuera de las instituciones bancarias...; finalmente añadió que .... la experiencia ha demostrado la imposibilidad práctica y el elevado costo administrativo que implica tratar de controlar los ingresos..., en particular los derivados del turismo y de las transacciones fronterizas. ${ }^{34}$

32

En lo sucesivo, en el mercado libre la moneda extranjera en billetes podria adquirirse en plazas fronterizas y en los aeropuertos internacionales. En plazas del interior sólo se podrian adquirir divisas en documentos. Cfr.: Diario Oficial del 13 de diciembre de 1982.

33

El día 20 de noviembre, cuando entró en vigor el decreto, el dólar en el mercado libre también se devaluó, se cotizó a 150 pesos.

34

Decreto de control de cambios, Diario Oficial, 13 de diciembre de 1982. 


\section{NUEVOS PROBLEMAS}

Son conocidas las implicaciones generales de la táctica mexicana seguida ante la crisis económica. Aquélla se inscribe dentro de las alternativas posibles admitidas por las autoridades del sistema financiero internacional. Nuestro programa de recuperación económica es así de corte restriccionista, con claros límites al crecimiento de los salarios (si bien no explícitos, sí implícitos y evidentes), con una clara tendencia a eliminar los subsidios al trabajo y simultáneamente transferir recursos al capital manufacturero endeudado en dólares. Si bien los grupos empresariales reclaman hoy el que no se hayan eliminado ya las empresas económicamente ineficientes del sector estatal y paraestatal, y la competencia desleal que hacen empresas del estado al sector comercial privado, a nadie escapa que en los primeros cien días de la nueva administración se ha dado clara muestra de la voluntad política de reducir el volumen si no la calidad de la intervención estatal en la economía, de rea. brir la banca nacionalizada al capital privado, de liberalizar el comercio ex. terior hasta donde lo permite la escasez de divisas, de eliminar los controles de precios, y de dejar que las economías campesinas se extingan lenta y natu. ralmente en este nuevo marco social. Todo ello dentro de un marco retóri. co anti-inflacionario.

En las últimas semanas de febrero nuevos problemas pusieron en duda la viabilidad del programa de recuperación mexicano. Las dificultades in. ternas de la OPEP desembocaron en la reducción del precio del petróleo en el mercado internacional. ${ }^{35}$ México encabeza así una larga lista de países atados a su deuda y en inminente riesgo además de ver reducidos, aún más sus ingresos por exportaciones. En estas condiciones nadie puede asegurar $\mathrm{e}$. desarrollo futuro de los acontecimientos. ${ }^{36}$.

35.

Cfr: The Unriqquing Oil Prices, Newsweek, marzo 7 de 1983.

36.

Mientras algunos analistas preven una estratégica consolidación de la deuda internacional, hay quien supone peligrosamente próximo el desplome del sistema financiero internacional, resultado de la im. posibilidad contable de hacerle frente a aquella deuda; ello cristalizaría, señalan en el desencadenamiento de una serie de c'efaults (más o menos involuntario) de países prestatarios.

Es clara la disyuntiva entre comer o pagar la deuda en que se encuentran los parses en cuestion; algunas voces locales incluso sugieren poner las necesidades nacionales por encima de los compromisos internacionales. Es claro que ello podría hacerse unilateralmente o de común acuerdo con otros países prestatarios. La acción conjunta supone la existencia previa de acuerdos internacionales entre países de muy diferente nivel de desarrollo y con diversos proyectos políticos, mientras que la acción unilateral orientada a la reducción o suspensión de pagos, ocasionaría consecuencias económicas y politicas desastrosas y dañaría significativamente la planta productiva nacional al abatir casi total. mente el comercio exterior. Cfr.: Declaraciones del Secretario de Hacienda mexicano, Jesus Silva Herzog, en Excélsior del 18 de marzo de 1983. La gravedad de la crisis impone, al margen de simpatías politicas, soluciones pragmáticas. 
En suma, las expectativas de recuperación económica en México parecen depender más de factores exógenos (recuperación económica estadunidense, caída de las tasas de interés, recuperación del mercado petrolero, etc.) que de decisiones y voluntades internas; asimismo se observa que es poco probable que tal recuperacion se logre en el corto plazo. ${ }^{37}$ Como quiera que sea, necesitará de intenso apoyo diplomático, sobre todo si se hacen necesarias decisiones multilaterales, y en cualquier caso requerirá de un esfuerzo nacional de magnitud desconocida hasta hoy a fin de superar los tradicionales niveles de ineficiencia productiva y corrupción administrativa, y a fin de contener las inevitables tendencias a la desintegración nacional.

En el corto plazo, si se descartan las alternativas inusitadas, es altamente probable una desaceleración generalizada del comercio exterior mericano, lo que tendrá, tiene ya, una influencia relevante en la reducción de los intercambios mercantiles entre México y los Estados Unidos, en especial en la reducción de las importaciones mexicanas de bienes estadounidenses. ${ }^{38}$ En suma, a fin de amortizar nuestra deuda, tendremos que exportar más, mucho más de lo que importemos; asi, se perfila explícitamente una estrategia forzada, pero no por ello menos definida, de sustitución de importaciones, la cual.si bien no estará apuntalada permanentemente por un peso subvaluado, tampoco aceptará nuevas sobrevaluaciones de nuestra moneda. ${ }^{39}$ Son asimismo previsibles el desarrollo próximo de nuevas exportaciones mexicanas, gas natural por ejemplo, y la apertura más o menos irrestricta a la inversión extranjera directa.

En la vertiente política, este escenario no puede dejar de acompañarse de la crisis en los aparatos tradicionales de control de la fuerza de trabajo. La creciente desocupación, el abatimiento de los salarios reales, y la desaparición de transferencias al trabajo, hacen prever la renegociación del virtual pacto social entre los gobiernos institucionales y las masas de trabajadores agrícolas y urbanos, la recomposición de las actuales centrales obreras y cam-

\section{7 \\ Informe del Banco Mundial sobre México. Hasta 1989 agobiará la deuda.}

38

Este escenario tenderá a agudizarse, además, si prosperan, por otra parte, las tendencias proteccionisto estadunidenses en contra de las precarias exportaciones no-petroleras mexicanas; es, por tanto, natural esperar que los exportadores mexicanos afectados insistan en la demanda de que México se incorpore al GATT.

39.

Hay que reconocer, sin embargo, el impacto favorable que en el largo plazo tendrá, en la planta industrial nacional, la sustitución de importaciones en los mercados locales y regionales fronterizos. 
pesinas, y la represión violenta de las manifestaciones políticas extremas; en suma, la reorientación de la vida social nacional.

Hemos apuntado arriba que los efectos de la crisis económica se amplifican en las formaciones sociales urbanas del norte de México. Habrá que añadir que además del impacto directo en los precios de los bienes importados provocado por la devaluación, el proceso de sustitución de las importaciones en el sistema global eleva el costo de vida y (en una primera instancia) abate la calidad de la vida de la población nacional; ello golpea especialmente a los cuatro millones de mexicanos que viven hoy en el extremo norte.

Además, con la nueva relación de cambio algunos artículos mexicanos. especialmente los intensivos en mano de obra, se vuelven atractivos para el consumidor estadounidense, es decir, se orientan al comprador no-local; el efecto inflacionario de tal proceso es significativo. La demanda local de algunos bienes se suma a la demanda vecina y el desabastecimiento empieza a caracterizar a aquellas localidades, de por sí irregularmente abastecidas con bienes nacionales.

En el futuro próximo las condiciones externas a la región dejan ver que la frontera no contará más con los dólares baratos que tuvo en otros años y que, por el contrario, deberá reorientar su demanda más o menos permanentemente al sistema productivo nacional. Aunque algunos grupos regionales logren restablecer por tiempo indefinido la zona libre u otro régimen fiscal comercial de excepción que les permita importar libres de impuestos, insumos, maquinaria y artículos electrodomésticos, ... no hay nada que el gobierno pueda hacer para otorgarles dólares baratos. ${ }^{40}$

En otras palabras, la población fronteriza deberá soportar con la del resto del país las implicaciones de la nueva política económica adoptada por el Estado nacional; aunque éste lo deseara no podrá hacer muchas concesiones reales a los intereses regionales. Todo parece indicar que la mayoría de la población fronteriza intuye las responsabilidades derivadas de la coyuntura; sin embargo, habrá que preguntarse si la burguesía regional aceptará la carga que - le corresponde llevar en la crisis o con qué instrumentos negociará con el gobierno federal la transferencia de sus responsabilidades a otros sectores sociales; convendrá indagar también si este proceso fortalecerá o no sus tenden-

40.

Miguel Mancera Aguayo, director del Banco de México, Excélsior, 16 de enero de 1983. 
cias hacia la autonomf́a política regional, si logrará una vez más hacer pasar sus intereses como los intereses generales de la región, ${ }^{41}$ y de ser así, ¿en qué grado podrá lograrlo?; y, finalmente, ¿cuáles son las posibilidades y limitaciones del Estado nacional mexicano en esta negociación? y ¿cuáles son los intereses regionales y federales estadounidenses en el desarrollo de la contradicción centro-periferia fronteriza?.

Es evidente que no podemos aquí dar respuesta a estas interrogantes. Sin embargo, a modo de conclusión podríamos anotar algunos elementos finales que en todo caso ayudarían a aclarar su formulación y a esbozar nuevos interrogantes.

De suyo, la relación política entre los poderes regionales y el poder central en una república federal o confederada es siempre difícil. Toda confederación debe ratificarse consuetudinariamente con hechos que muestren a los habitantes de los diversos estados que su proyecto regional de desarrollo se engrandece y acelera dentro del proyecto nacional. Si ello no se dá, el pacto federal se debilita y crecen las tendencias al separatismo y a la autarqufa.

Si bien la estructura social mexicana, vista en conjunto, se caracteriza por la debilidad del conjunto de organizaciones que los especialistas denominan sociedad civil y, consecuentemente, por la fortaleza relativa del aparato de estado y su tendencia a ocupar todos los espacios de la vida social, en las comunidades fronterizas estos rasgos parecen darse desdibujados y a niveles menores. ${ }^{42}$ Por una parte, el poder federal frecuentemente materializa alli en diluídas representaciones ministeriales y en empleados y funcionarios de memoria poco grata (por ejemplo, todo tipo de policías federales, empleados aduanales, e inspectores del llamado Registro Federal de Automóviles)

41.

Los acontecimientos recientes muestran cómo los intereses del sector privado regional, afectado por la desaceleración de los intercambios comerciales, fueron presentados como los intereses globales de la región, afectados por la incomprensión del centro. Los intereses de los trabajadores regionales, por ejemplo, no recibieron el mismo tratamiento periodístico.

42.

Las comunidades que agrupamos bajo el rubro de fronterizas son notoriamente heterogéneas y es equívoco, por tanto, generalizar hechos que si bien pueden ser local o regionalmente exactos, podrian ser erróneos aplicados a otras localidades o al conjunto de ellas. Por ello, interesa aclarar que en lo que sigue nos referimos a hechos claramente observables en el extremo noroeste de México. Sobre estas generalizaciones erróneas véase: Jesús Tamayo y Berta Helena de Buen Some Mistaken concepts about México's Northern Border Working Paper Series, Overseas Development Council, Washington, D.C. 1982. 
por otra parte, la relativamente débil presencia local del Estado ${ }^{43}$ deja un mayor margen de acción a las organizaciones locales propiamente civiles que, además, viven el efecto-demostración de la vecina democracia estadounidense.

En algunas regiones del extremo norte de México la relación con los poderes centrales es aún más complicada en tanto se ha desarrollado allí una cierta simbiosis entre la clase polf́tica y el sector empresarial locales. ${ }^{44}$ En tanto este sector se ha visto inmerso en los últimos años en un proceso de creciente asociación económica con su vecina contraparte estadounidense, y en este proceso ha aprendido a alinearse culturalmente con los modelos socio-culturales vecinos, en la medida en que penetra en los aparatos políticos locales aparecen dentro del conjunto de los intereses regionales la defensa y promoción de los intereses estadounidenses en la región. ${ }^{4}$

La crisis actual precipita el surgimiento de una agresiva sociedad civil. En el norte de Mexico, su eventual agresividad ante el sistema se agudizará tal vez porque el centro se ha dejado frecuentemente representar por funcionarios ineficientes, cuando no corruptos, y porque el poder local con no poca frecuencia encabeza la defensa del interés externo. Si esta situación se perpetúa, ¿cuánto se habrá de pagar en el futuro por ello? ${ }^{46}$

Hemos señalado en otras partes la necesidad de que el estado mexicano haga suya la cuestión fronteriza y la erija en una cuestión de Estado. Habría que añadir hoy que la nacionalización de la clase política fronteriza se revela requisito indispensable cuando nuestro país necesita hacer acopio de sus recursos morales para enfrentar la crisis y las presiones externas, y cuando se prevé que las sociedades fronterizas deberán resistir más que nadie, la reducción de sús niveles tradicionales de vida y al mismo tiempo reafirmar su comunidad de intereses y de destino con el resto de la nación mexicana.

43.

La presencia del Estado no la medimos ciertamente por el número de funcionarios o empleados pú blicos en una cierta región sino principalmente por su densidad política y por la legitimidad de su fun ción social.

44.

No es casual que en las listas recientes de aspirantes a candidatos del partido oficial a la gubernatur: del Estado de Baja California Norte, la abrumadora mayoría la hayan integrado distinguidos persona jes del sector empresarial regional.

45

Ello explica que desde el gobierno estatal se proteja la existencia de una legislación laboral de excep ción para las maquiladoras y, a últimas fechas, se solicite a la Secretarła de Hacienda la reducción di impuestos federales a los estadounidenses asentados allí, y la eliminación de los retenes en las aduana: fronterizas a fin de no alterar el flujo de salida de bienes básicos. 46.

Hasta hoy, la organización civil surge de las capas medias que sugieren la desobediencia al poder público. Junto a ella se observa a la oposición de derecha, en ciertos sectores favorable a ideas autonomistas. El Partido de Accion Nacional ha encabezado la desobediencia civil en las últimas semanas respaldando el rechazo al pago por tenencia de automóviles y por incrementos en las tarifas por consumo de energía eléctrica. 